\title{
One-step green synthesis of antibacterial silver nanoparticles embedded in electrospun cyclodextrin nanofibers
}

\author{
Asli Celebioglu, Fuat Topuz, Zehra Irem Yildiz, Tamer Uyar* \\ Institute of Materials Science \& Nanotechnology, UNAM-National Nanotechnology Research Center, Bilkent University, 06800 Ankara, Turkey
}

\section{A R T I C L E I N F O}

\section{Keywords:}

Cyclodextrin

Nanofibers

Electrospinning

Silver nanoparticles

Green synthesis

Antibacterial

\begin{abstract}
A B S T R A C T
Antibacterial electrospun nanofibers based on cyclodextrin (CD) and silver nanoparticles (Ag-NPs) were produced by solution electrospinning from aqueous and DMF solutions using different Ag contents. CD molecules acted as the reducing agent and catalyzed the formation of Ag-NPs. The nanofibers with smaller diameters were observed for the fibers generated from DMF solutions than those produced from aqueous solutions. TEM and STEM analyses revealed the Ag-NPs ( $\sim 2-5 \mathrm{~nm}$ depending on solvent-type and Ag loading) in nanofibers, while FTIR and surface enhanced Raman scattering (SERS) analyses showed the apparent frequency shift of OH stretching band and the enhancement of Raman bands of CD molecules with the incorporation of the Ag-NPs. The polycrystalline structure of the Ag-NPs was shown by XRD and SAED analyses over $\{111\},\{200\},\{220\}$ and \{311\} planes. The nanofibers showed significant inhibition against the growth of Escherichia coli and Staphylococcus aureus owing to the antibacterial activity of the Ag-NPs.
\end{abstract}

\section{Introduction}

Antibacterial materials have taken considerable interest in targeting pathogenic bacteria in daily life and protecting human health (Li, Chen, Zhao, \& Urmila, 2015). Particularly, pathogenic bacteria like Escherichia coli (E. coli) and Staphylococcus aureus (S. aureus) can lead to lifethreatening diseases, e.g., clinical mastitis (Bannerman et al., 2004). Although most types of $E$. coli are considered as harmless and commonly found in the lower intestine, some types can lead to various intestinal and extraintestinal illnesses through virulence factors, such as yersiniabactin, aerobactin, flagellin and intimin (Kaper, Nataro, \& Mobley, 2004). Particularly, the pathotypes of E. coli can provoke diseases like dysentery (Chanter, Hall, Bland, Hayle, \& Parsons, 1986) and diarrhoea (Levine, 1987). On the other hand, S. aureus was listed as one of high-priority pathogens by the World Health Organization (WHO). In this regard, various drug molecules (Ruszczak \& Friess, 2003), antibiotics (Williamson, Maroudas, \& Wilkie, 1971), nanoparticles (Wang, $\mathrm{Hu}$, \& Shao, 2017), quaternary ammonium compounds (Makvandi, Jamaledin, Jabbari, Nikfarjam, \& Borzacchiello, 2018), metal ions (Du, Niu, Xu, Xu, \& Fan, 2009), a water-soluble antibacterial polysaccharide extracted from dandelion and its derivative (Lin, Zhu, Li et al., 2018), essential oils (thyme (Lin, Zhu, Thangaraj, Abdel-Samie, \& Cui, 2018), and tea tree oil (Cui, Bai, \& Lin, 2018)), clove oil/chitosan nanoparticles (Cui, Bai, Rashed, \& Lin, 2018), nisin-loaded nanoparticles
(Cui, Wu, Li, \& Lin, 2017), and cinnamon essential oil/beta-cyclodextrin ( $\beta$-CD) proteoliposomes (Lin, Dai, \& Cui, 2017) were exploited to inhibit bacterial growth and destroy the cellular structure of microorganisms. Apart from the above biocides, silver nanoparticles (Ag-NPs) have also shown high antibacterial activity, and therefore, were incorporated into different material systems, including hydrogels (González-Sánchez et al., 2015; Lustosa et al., 2017), nanogels (Qasim, Udomluck, Chang, Park, \& Kim, 2018), and coatings (Zhao et al., 2011). They were also incorporated into electrospun fiber systems to generate antibacterial nanofibrous materials. In this regard, various Ag-loaded electrospun fibers based on a polymer and $\mathrm{Ag}$ precursors were previously reported (Patel, Li, Wang, Zhang, \& Wei, 2007; Rujitanaroj, Pimpha, \& Supaphol, 2008; Son, Youk, Lee, \& Park, 2004; Xu et al., 2006).

The formation of Ag-NPs through the reduction of $\mathrm{Ag}$ (II) can take place in the presence of a reducing agent, such as polyols, or by heat treatment. In this context, Hong et al. reported poly(vinyl alcohol) (PVA) fibers containing Ag-NPs, which were prepared by the electrospinning of PVA/silver nitrate $\left(\mathrm{AgNO}_{3}\right)$ and subsequent heat treatment (Hong, Park, Sul, Youk, \& Kang, 2006). Zhuang et al. produced Ag-NPs containing chitosan/gelatin nanofibers, where the nanoparticles sizing between 1 and $5 \mathrm{~nm}$ were synthesized using a microcrystalline chitosan as the reducing agent (Zhuang, Cheng, Kang, \& Xu, 2010). An interesting study on the use of solvent as a reducing agent was reported by

\footnotetext{
* Corresponding author.

E-mail address: tamer@unam.bilkent.edu.tr (T. Uyar).
} 
Zhang and co-workers (Shi et al., 2011). The authors used formic acid as the reducing agent for $\mathrm{AgNO}_{3}$ and solvent for the dissolution of nylon- 6 to obtain electrospun fibers loaded with Ag-NPs sizing between 2 and $4 \mathrm{~nm}$. Li et al. reported the synthesis of Ag-NPs with the help of a chitosan oligosaccharide and their addition to PVA solutions prior to the electrospinning (Li et al., 2013). The Ag-NPs were produced in the size range of 15-22 nm, and the resultant nanofiber mats were used as a bioactive wound dressing material. A similar concept was exploited for the preparation of Ag-NPs loaded fibers using glucose and chitosan as reducing and protective agents (Abdelgawad, Hudson, \& Rojas, 2014). The synthesis of the Ag-NPs was performed at $95^{\circ} \mathrm{C}$ using $\mathrm{AgNO}_{3}$ as a precursor. The Ag-NPs $(\sim 25 \mathrm{~nm})$ were blended with PVA and electrospun into nanofibers with a mean size of $150 \mathrm{~nm}$. The nanofibers were later treated with glutaraldehyde for cross-linking and tested against $E$. coli. Destaye et al. described an interesting method for the synthesis of Ag-NPs on the cross-linked PVA fibers (Destaye, Lin, \& Lee, 2013). The electrospun PVA fibers were cross-linked with glutaraldehyde and kept in the solution of $\mathrm{AgNO}_{3}$ overnight at room temperature. Over time, the color of the fiber mat changed to grayish, suggesting the formation of nanoparticles on the fibers. Even though the presence of several approaches for the preparation of $\mathrm{Ag}$ nanoparticles loaded electrospun fiber systems through mostly a multistep process in the presence of additional reducing agents, there is an increasing demand for the preparation of such antibacterial fibers through facile and green routes with tailor-made properties. In this regard, the use of CD molecules as a reducing agent allows the synthesis of size-tunable Ag-NPs and stabilizes them against precipitation. This enables the homogenous distribution of the formed Ag-NPs in the fiber matrix. Moreover, the mixture could be electrospun into functional fibers that can be used in different applications, e.g., drug delivery and water treatment, in addition to their antibacterial application.

In this paper, we show a facile and green approach using $\mathrm{CD}$ molecules as the building blocks for nanofibers and reducing agent at the same time, while silver nitrate $\left(\mathrm{AgNO}_{3}\right)$ was used as an $\mathrm{Ag}$ precursor. $\mathrm{CD}$ is a cyclic oligomer of glucose obtained by enzymatic degradation of starch and has been used in a diverse range of applications due to their host-guest supramolecular complexation ability (Crini, 2014; Sharma \& Baldi, 2016). Further, CDs have been used as functional molecules to synthesize environmentally benign nanomaterials (Prochowicz, Kornowicz, \& Lewiński, 2017). Likewise, they were exploited for the synthesis of Ag-NPs (de Souza, Barros, Tasic, Gimenez, \& Teixeira Camargo, 2018). Under alkaline conditions, CD can catalyze the reduction of $\mathrm{Ag}(\mathrm{II})$ to metallic $\mathrm{Ag}(0)$ without the requirement of any reducing agent and lead to the formation of Ag-NPs. In this regard, the use of $\mathrm{CD}$ molecules as the reducing agent for the synthesis of noble metal nanoparticles in either acidic or alkaline media was reported (Celebioglu \& Uyar, 2013; Devi \& Mandal, 2013; Huang, Meng, \& Qi, 2009; Martin-Trasanco, Cao, Esparza-Ponce, Montero-Cabrera, \& Arratia-Pérez, 2017; Pande et al., 2007). According to Pande et al., the basic mechanism was explained by the deprotonation of hydroxy groups of $\mathrm{CD}$ at alkaline solutions, which promoted the synthesis of nanoparticles. Whereas, Devi et al. reported that the particle synthesis takes place when the solution pH is about 10 (Devi and Mandal, 2013).

In this study, the nanocomposite $\mathrm{CD} / \mathrm{Ag}-\mathrm{NP}$ electrospun nanofibers were produced from aqueous and DMF solutions at two different $\mathrm{Ag}$ loadings (1 and $2 \mathrm{wt} . \%$ ), and characterized in terms of fiber morphology by SEM, and the distribution of the Ag-NPs by TEM and STEM. UV-vis and SERS analyses were carried out to confirm the presence of the Ag-NPs in the nanofibers. The chemical composition of the Ag-NPs was studied by FTIR, chemical state of Ag by XPS, and the crystallinity of the nanoparticles through XRD. The antibacterial activity of the nanofibers was tested against $E$. coli and $S$. aureus over $24 \mathrm{~h}$ treatment.

\section{Experimental section}

\subsection{Materials}

Hydroxypropyl- $\beta$-cyclodextrin (HP- $\beta$-CD, Cavasol $^{\circledR}$ W7 HP, with a substitution degree between 0.6 and 0.9 ) was received from Wacker Chemie AG (Germany) as a gift sample. The solubility of the HP- $\beta$-CD is $\sim 2300 \mathrm{~g} / \mathrm{L}$ at $24^{\circ} \mathrm{C}$ according to the producer. Silver nitrate $\left(\mathrm{AgNO}_{3}\right.$, $\geq 99.5 \%$, Sigma Aldrich), N, N-dimethylformamide (DMF, Riedel) and sodium hydroxide ( $\mathrm{NaOH}, \geq 98 \%$, Fluka) were obtained and used as received. Distilled water was produced by a Millipore Milli-Q Ultrapure system.

\subsection{Electrospinning of $A g-N P s$ embedded $H P-\beta-C D$ nanofibers}

First, HP- $\beta$-CD was dissolved in DMF $(120 \%(w / v))$ or water $(160 \%$ $(\mathrm{w} / \mathrm{v}))$ to produce bead-free nanofibers (Celebioglu \& Uyar, 2012). Afterwards, $\mathrm{AgNO}_{3}$ (1 and 2 wt. $\%$ with respect to elemental $\mathrm{Ag}$ over $\mathrm{CD}$ content) was added. After the solutions were homogenized, the $\mathrm{pH}$ was adjusted to $\sim 9$ with $1 \mathrm{M} \mathrm{NaOH}$. Thereafter, the solutions were kept stirring overnight until their color turned to dark-brown, suggesting the formation of Ag-NPs in the HP- $\beta$-CD solutions. The solutions were transferred into $3 \mathrm{~mL}$ syringes having metallic needles with an inner diameter of $0.60 \mathrm{~mm}$. The syringes were positioned horizontally on a syringe pump (Model: SP 101IZ, WPI) and a high voltage power supply (Matsusada, Precision, AU Series) was used for the electrospinning. During the electrospinning process, the following parameters were used: the applied electrical voltage was $15 \mathrm{kV}$, the tip-to-collector distance was $15 \mathrm{~cm}$, and the flow rate kept at $0.5 \mathrm{~mL} / \mathrm{h}$. The nanofibers were collected on a ground collection plate of aluminium foil at $24^{\circ} \mathrm{C}$. The pure HP- $\beta$-CD nanofibers were also produced as a control sample without using Ag precursor from the aqueous and DMF solutions of HP$\beta$-CD at the same concentration $(120 \%(w / v)$ in DMF and $160 \%(w / v)$ in water) for electrospinning.

\subsection{Characterization}

Scanning electron microscopy (SEM, Quanta 200 FEG, FEI) was used to explore the morphology of the nanofibers. The fiber samples were coated with a thin layer of $\mathrm{Au} / \mathrm{Pd}(\sim 5 \mathrm{~nm})$ using a Gatan 682 Precision Etching and Coating System (PECS). The mean diameters $(<D>)$ of nanofibers and their size distributions were calculated over ca. 100 fibers from SEM images by ImageJ (NIH, Bethesda, MD, USA). Transmission electron microscopy (TEM, FEI-Tecnai G2F30) was used for the observation of the Ag-NPs in the nanofibers. For TEM imaging, the nanocomposite nanofibers were directly collected on TEM grids. The particles were analyzed by a GATAN Digital Micrograph software. X-Ray diffraction experiments were performed using a PANalytical X'Pert Pro MPD, which was powered by a Philips PW3040/60 X-ray generator and fitted with an X'Celerator detector. The X-rays were generated from a Cu anode supplied with $40 \mathrm{kV}$ and a current of $40 \mathrm{~mA}$. The data were collected in the $2 \theta$ range of $10-80^{\circ}$ using a scanning $\mathrm{X}$ 'Celerator detector and analyzed by PANalytical High Score Plus software (version 2.0). The X-ray photoelectron spectra of the nanofibers were recorded with an X-ray photoelectron spectrometer (XPS, Thermo Scientific). XPS was used by means of a flood gun charge neutralizer system equipped with an $\mathrm{Al} \mathrm{K}-\alpha$ X-ray source ( $h v=1486.6 \mathrm{eV}$ ). For the spectral regions of $\mathrm{Ag}$, high-resolution spectra were recorded at a pass energy of $50 \mathrm{eV}$. The FTIR spectra were recorded on a Fourier transform infrared (FTIR) instrument (BrukerVERTEX 70). The samples were mixed with potassium bromide ( $\mathrm{KBr}$ ) and pressed into pellets. A total of 64 scans were collected between 4000 and $400 \mathrm{~cm}^{-1}$ at a resolution of $4 \mathrm{~cm}^{-1}$. The UV-vis absorption spectra of the nanofibers were taken with a Varian Cary 5000 UV-vis-NIR spectrometer. The UV-vis spectra of the nanofibrous mats were obtained at solid and liquid states, and the background was 
corrected with the pure HP- $\beta$-CD nanofibers. The SERS measurements were carried out on the nanofibers with a WITEC Alpha 300S Raman module. A diode-pumped solid-state laser $(532 \mathrm{~nm})$ was used for excitation in Raman measurements. The laser power was measured using a silicon photodiode at the sample plane. Power densities were calculated using an apparent spot diameter of the illumination area.

\subsection{Antibacterial tests}

The antibacterial activity of the electrospun nanofibers generated from aqueous solutions with different Ag loadings (1 and $2 \mathrm{wt} . \%$ ) was tested against Gram-negative bacteria, Escherichia coli RSHM 888 (RSHM, National Type Culture Collection Laboratory, Ankara, Turkey) and Gram-positive bacteria, Staphylococcus aureus RSHM 96090/07035 (ATCC 25923) using the agar-diffusion method. The bacteria (E. coli and $S$. aureus) were grown overnight and of which $150 \mu \mathrm{L}\left(\sim 10^{7} \mathrm{cfu} /\right.$ $\mathrm{mL}$ of $E$. coli and $\sim 10^{9} \mathrm{cfu} / \mathrm{mL}$ of $S$. aureus) poured on the Luria-Bertani (LB) agar plates. Afterwards, the circular fiber samples (diameter $=6$ $\mathrm{mm}$ ) were placed on the agar plates and incubated at $37^{\circ} \mathrm{C}$ for $24 \mathrm{~h}$. Then, the diameters of the inhibition zone (i.e., transparent area) were measured. All experiments were performed in triplicates.

\section{Results and discussion}

$\mathrm{Ag}$-NPs were synthesized over the reduction of $\mathrm{Ag}^{2+}$ to $\mathrm{Ag}^{\circ}$ by the alkaline solutions of CD molecules after overnight mixing (Fig. 1a and b). The formation of Ag-NPs can be visualized by the color change to dark-brown (Fig. 1b) (Kim et al., 2007; Sanghi \& Verma, 2009; VilchisNestor et al., 2008). The electrospinning of the colored solution led to a brownish fiber mat (Fig. 1c and d). On the other hand, the color of the fiber mat produced by only HP- $\beta$-CD molecules was white (Celebioglu \& Uyar, 2012). Thus, this color change can be attributed to the presence of Ag-NPs in the nanofibers.

Fig. 2 shows the nanofiber mats generated by the electrospinning of HP- $\beta$-CD/Ag-NPs nanocomposite solutions from DMF and aqueous solutions at different $\mathrm{Ag}$ loadings. The nanofiber mats electrospun from DMF solution have yellowish appearance, while nanofiber mats produced from aqueous solutions are greyish in color. This may be attributed to the size of Ag-NPs where bigger nanoparticles were formed
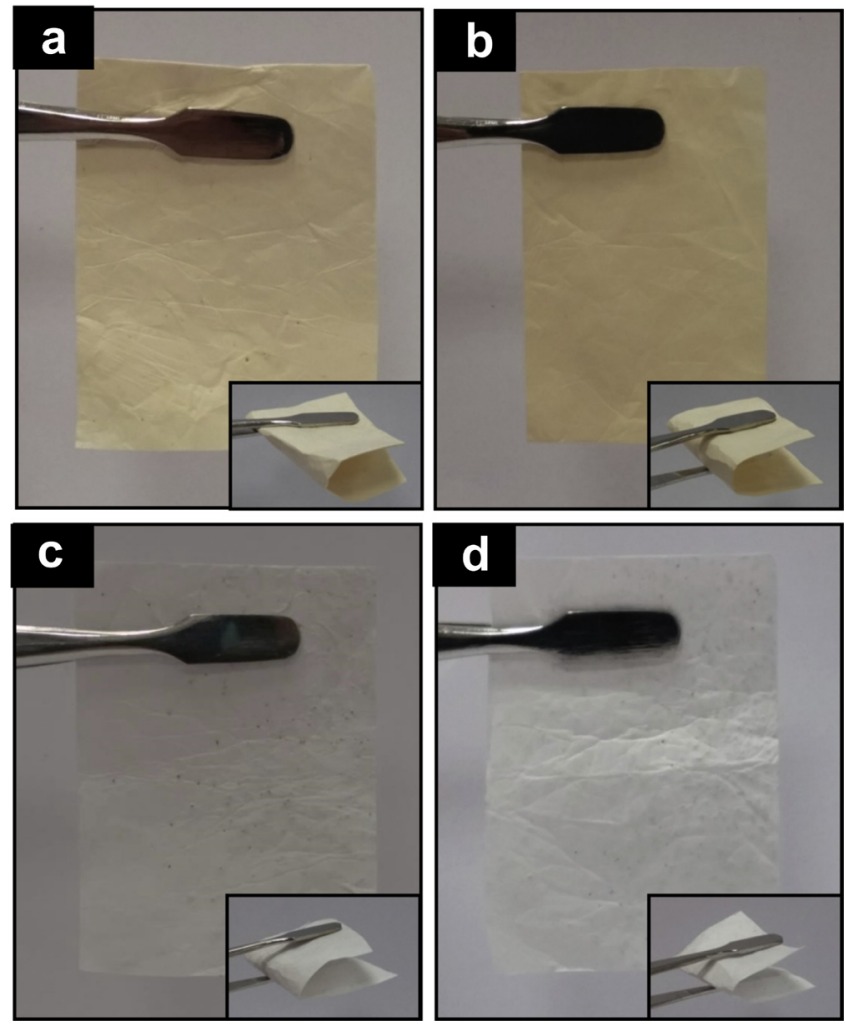

Fig. 2. The optical photos of the HP- $\beta$-CD/Ag-NPs nanofiber mats produced at different formulations. The HP- $\beta$ - $\mathrm{CD} / \mathrm{Ag}$-NPs nanofiber mats produced from DMF solutions at two different Ag loadings: (a) 1 and (b) 2 wt.\%. The HP- $\beta$-CD/ Ag-NPs nanofiber mats electrospun from aqueous solutions at two different $\mathrm{Ag}$ loadings: (c) 1 and d) $2 \mathrm{wt} . \%$. Insets show the optical photos of the folded mats.

in DMF. Both nanofiber mats could be folded without any structural damage, demonstrating the self-standing and flexible structure of the HP- $\beta$-CD/Ag-NPs nanofibers despite their polymer-free structure.

Regardless of the solvent type and Ag content used, all nanofibers
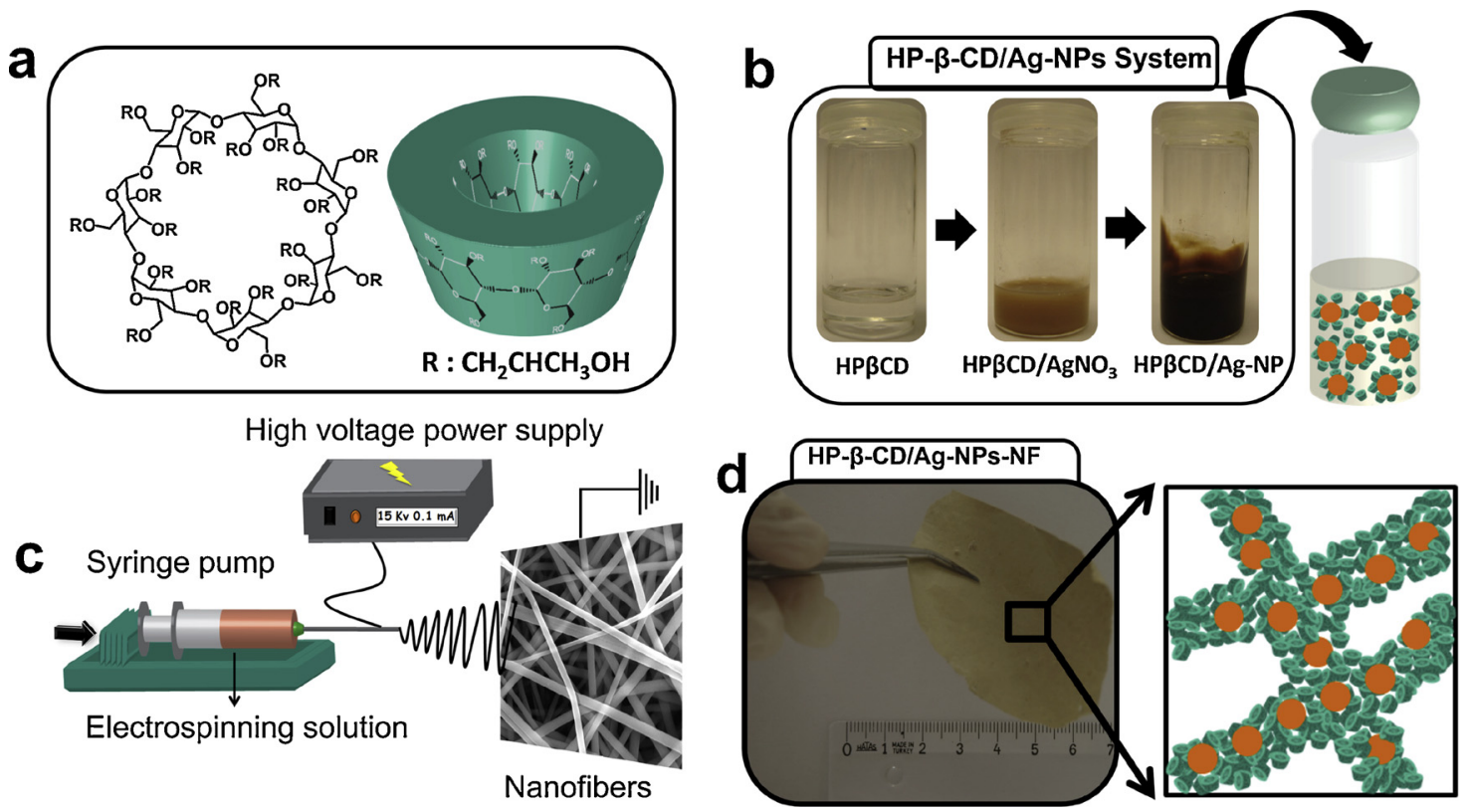

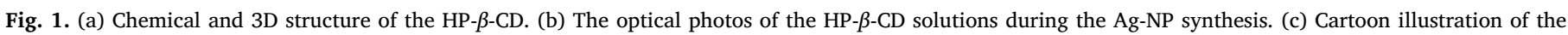

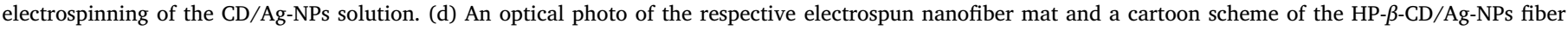
matrix. 

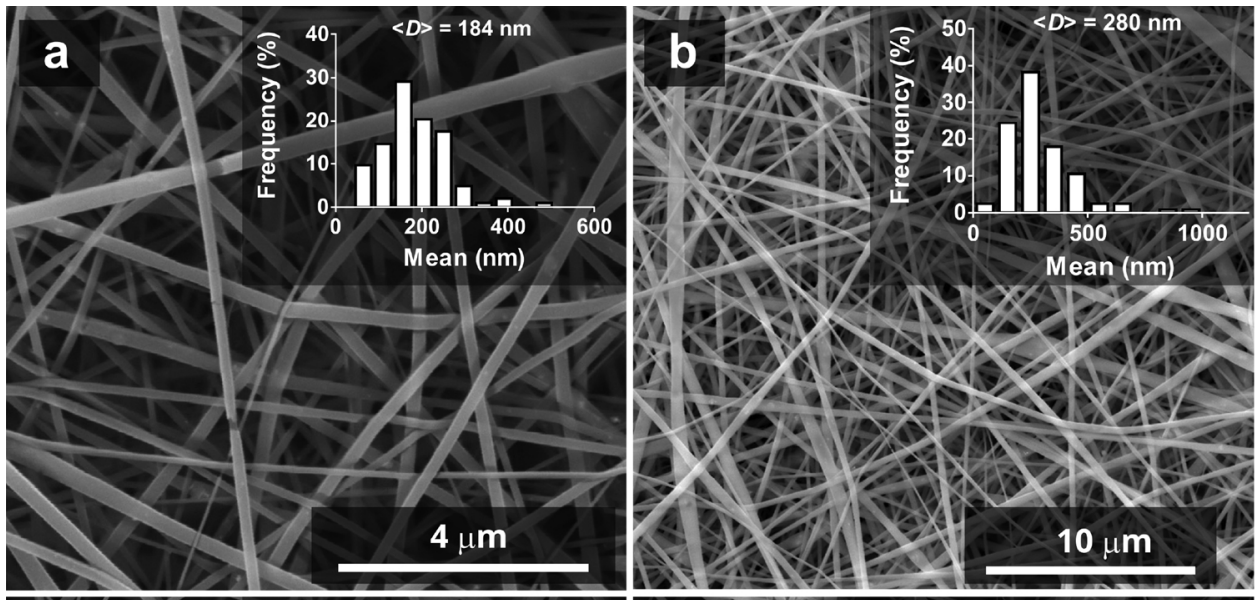

Fig. 3. Scanning electron micrographs of the HP- $\beta$-CD/Ag-NPs nanofibers. The nanofibers produced from DMF solutions at two different Ag loadings: (a) 1 and (b) 2 wt.\%. The nanofibers produced from aqueous solutions at two different Ag loadings: (c) 1 and d) 2 wt. $\%$. Insets show the size distributions of the respective nanofibers.
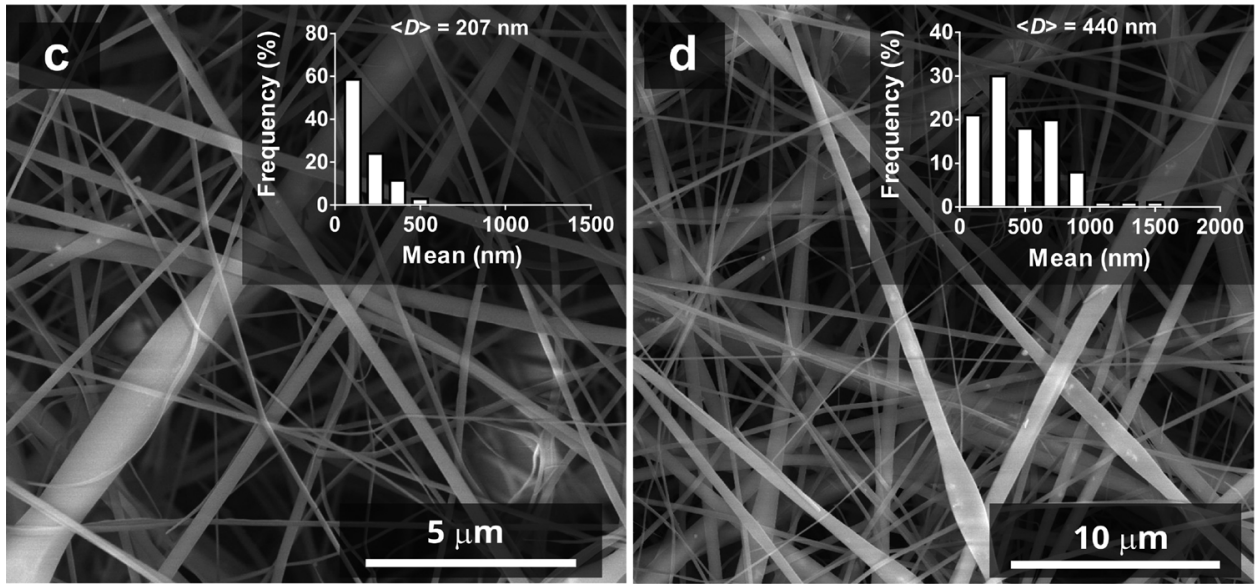

have bead-free structures as confirmed by SEM analyses (Fig. 3). The nanofibers produced from DMF solutions were smaller in diameter than those generated from aqueous solutions. Whereas, an opposite trend was observed for the Ag-free HP- $\beta$-CD fibers: the nanofibers produced from DMF solutions were almost monodisperse and larger than those electrospun from aqueous solutions (Celebioglu \& Uyar, 2012). The mean size of the nanofibers produced from DMF solutions increased from $\sim 184$ to $\sim 280 \mathrm{~nm}$ with an increasing $\mathrm{Ag}$ loading by two-fold from 1 to $2 \mathrm{wt} . \%$. A similar increase with Ag loading was observed for the nanofibers produced from aqueous solutions: the mean fiber diameter increased from $\sim 207$ to $\sim 440 \mathrm{~nm}$ with an $\mathrm{Ag}$ content rise from 1 to $2 \mathrm{wt} . \%$. The formation of larger nanofibers for the fibers electrospun from aqueous solutions can be attributed to their higher concentrations, i.e., $160 \mathrm{wt}$ \% whereas the fibers electrospun from DMF solutions could be produced at $120 \mathrm{wt} . \%$.

The morphology, size and distribution of the Ag-NPs were explored by electron microscopy. Fig. 4 shows the TEM and STEM images of the HP- $\beta$-CD/Ag-NPs nanofibers produced at different formulations. The presence of homogeneously dispersed, uniform Ag-NPs throughout the fiber matrix was clearly visible in both TEM and STEM images. With increasing Ag loading, Ag-NPs appeared denser for both solvent systems. Smaller Ag-NPs were observed for the fibers produced from aqueous solutions than those electrospun from DMF solutions. The mean size of the Ag-NPs in the fiber matrix produced from DMF solutions was measured as $\sim 3.5 \mathrm{~nm}$ for $1 \mathrm{wt} . \% \mathrm{Ag}$ loading and increased to $\sim 4.8 \mathrm{~nm}$ for $2 \mathrm{wt} . \% \mathrm{Ag}$ loading (Fig. $4 \mathrm{~g}(\mathrm{i}$-ii)). Likewise, for the nanofibers electrospun from aqueous solutions, the mean particle size increased from $\sim 1.9$ to $\sim 2.3 \mathrm{~nm}$ with an $\mathrm{Ag}$ content rise from 1 to $2 \mathrm{wt}$. $\%$, respectively (Fig. $4 \mathrm{~g}$ (iii-iv)). The formation of larger Ag-NPs in DMF solutions can be attributed to the reducing role of DMF. In this regard, Pastoriza-Santos et al. reported the formation and stabilization of silver nanoparticles through the reduction by DMF (Pastoriza-Santos \& LizMarzán, 1999). The HRTEM images of the Ag-NPs clearly demonstrate the presence of crystal fringes on the nanoparticles (Fig. 4). For both solvent systems, the HRTEM images of the nanoparticles reveal the dominantly exposed plane of $\{111\}$ of a face-centered cubic (fcc) $\mathrm{Ag}$ with the corresponding interplane spacing of $0.235 \mathrm{~nm}$ (Huang, Yang, Zhang, \& Xiao, 2016).

Table 1 summarizes the characteristics of the Ag-NPs embedded HP$\beta$-CD nanofibers produced at different formulations. The electrospinning from DMF solutions requires lower HP- $\beta$-CD content ( $\sim 120 \mathrm{wt} . \%$ ), whereas the electrospinning from aqueous solutions requires a HP- $\beta$-CD concentration of $160 \mathrm{wt} . \%$ to form bead-free nanofibers due to the higher viscosity of the respective mixture in DMF, i.e., higher intermolecular interactions (Celebioglu \& Uyar, 2012). The mean size of the nanofibers and Ag-NPs showed variations depending on the solvent type and Ag content used: both increased with increasing Ag content for the nanofibers electrospun from DMF and aqueous solutions.

The presence of the Ag-NPs in the nanofiber matrix was also confirmed by solid-state UV-vis spectra (Fig. 5). Owing to the characteristic surface plasmonic resonance (SPR) band of metallic Ag-NPs, UV-vis spectra display a broad absorption peak between 300 and $500 \mathrm{~nm}$ for the Ag-NPs sizing in the range of $2-5 \mathrm{~nm}$, which is consistent with literature reports (Bhui et al., 2009). As clearly seen in Fig. 5a, a strong broad peak was visible in the respective range because of the in situ formed Ag-NPs. The wavelength of the absorption peak is directly related to the particle size: larger nanoparticles induce a bathochromic shift in the spectrum (Maciollek \& Ritter, 2014). Therefore, the absorption maximum of the HP- $\beta$-CD/Ag-NPs nanofibers from DMF solutions shifted to longer wavelengths owing to the formation of larger Ag-NPs. Similar absorption spectra were obtained from the UV-vis spectra of the HP- $\beta$-CD/Ag-NPs solutions (Fig. $5 \mathrm{~b}$ ). 

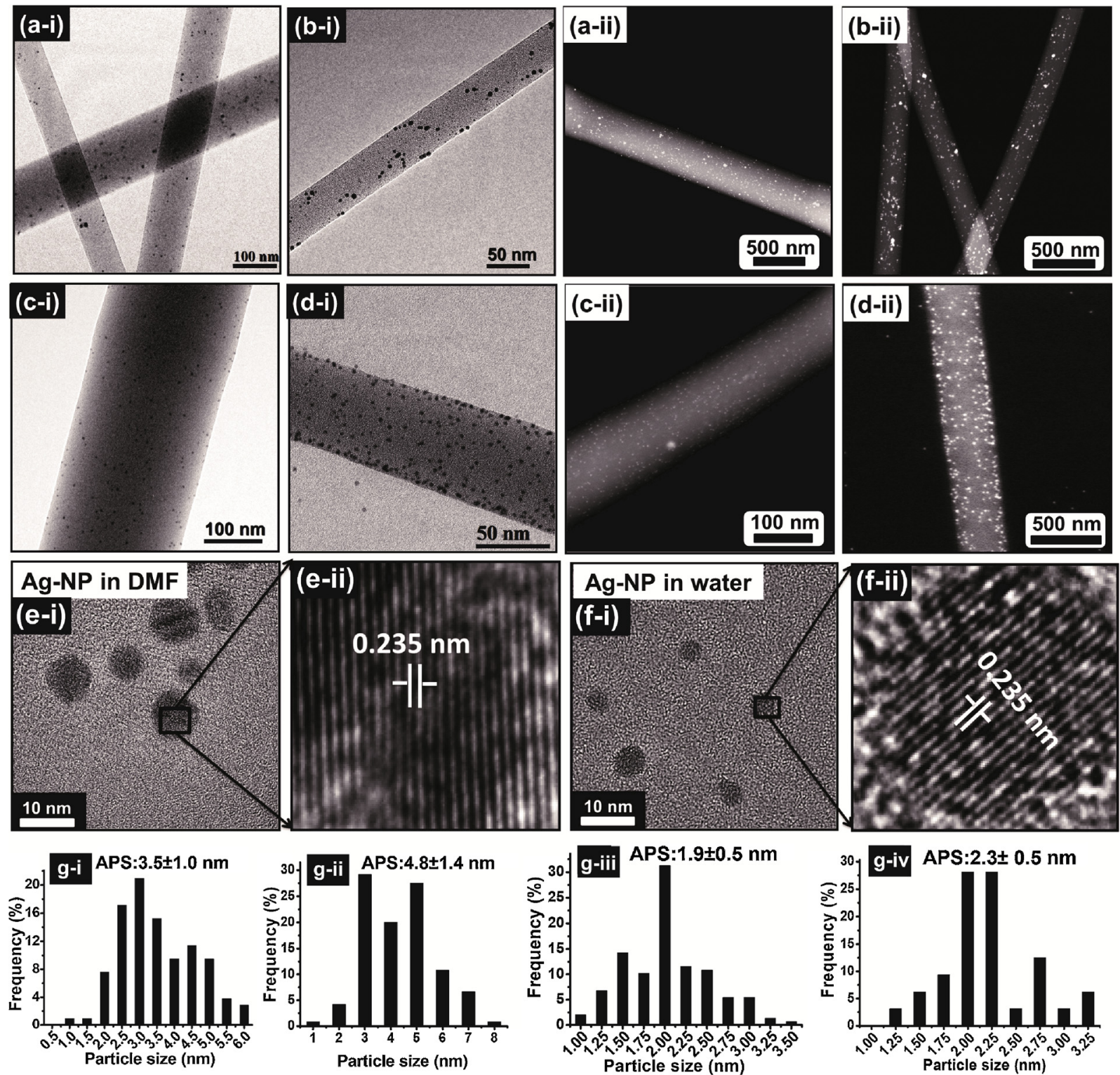

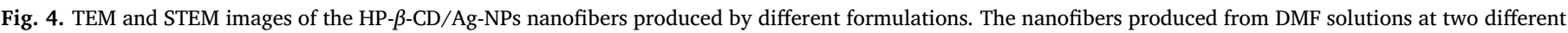

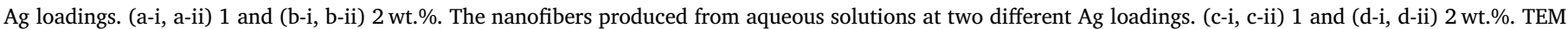

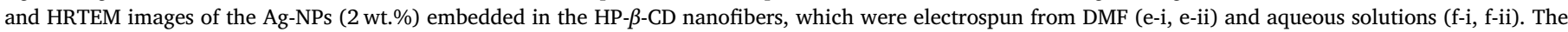

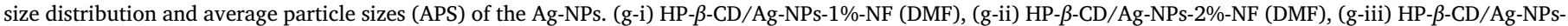
$1 \%$-NF (water) and (g-iv) HP- $\beta$-CD/Ag-NPs- $2 \%$-NF (water).

FTIR analysis was carried out to explore interactions between HP- $\beta$ $\mathrm{CD}$ and Ag-NPs in the HP- $\beta$-CD/Ag-NPs nanofibers. Fig. 6 shows the FTIR spectra of the HP- $\beta$-CD/Ag-NPs nanofibers where the $\mathrm{OH}$ stretching band of HP- $\beta$-CD molecules shifted to lower frequency owing to the interactions between $\mathrm{OH}$ groups of $\mathrm{CDs}$ and Ag-NPs. The pure HP- $\beta$-CD nanofibers revealed a broad peak centered at $3427 \mathrm{~cm}^{-1}$ due to the stretching vibration of $\mathrm{OH}$ groups. Upon addition of the Ag-NPs, it shifted to $3419 \mathrm{~cm}^{-1}$ for $1 \mathrm{wt} . \% \mathrm{Ag}$ loading and $3413 \mathrm{~cm}^{-1}$ for $2 \mathrm{wt} . \%$ $\mathrm{Ag}$ loading for the nanofibers produced from DMF solutions. On the other hand, the peak shifted to 3417 and $3411 \mathrm{~cm}^{-1}$ for the HP- $\beta$-CD/ Ag-NPs nanofibers produced from aqueous solutions with 1 and $2 \mathrm{wt} . \%$ $\mathrm{Ag}$ loadings, respectively. These shifts suggest the presence of

Table 1

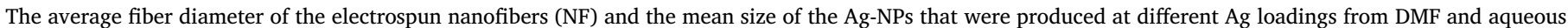
solutions. The values are expressed as mean \pm SD.

\begin{tabular}{|c|c|c|c|c|c|}
\hline Sample & Solvent & HP- $\beta$-CD concentration $(\%, w / v)$ & $\begin{array}{l}\text { NP concentration } \\
(\%, w / w)\end{array}$ & Mean fiber diameter (nm) & Average nanoparticle size (nm) \\
\hline HP- $\beta$-CD/AgNPs-1\%-NF & DMF & 120 & 1 & $184 \pm 45$ & $3.5 \pm 1.0$ \\
\hline HP- $\beta$-CD/AgNPs- $2 \%-\mathrm{NF}$ & DMF & 120 & 2 & $280 \pm 85$ & $4.8 \pm 1.4$ \\
\hline HP- $\beta$-CD/AgNPs- $1 \%-\mathrm{NF}$ & Water & 160 & 1 & $207 \pm 125$ & $1.9 \pm 0.5$ \\
\hline HP- $\beta$-CD/AgNPs- $2 \%-\mathrm{NF}$ & Water & 160 & 2 & $440 \pm 160$ & $2.3 \pm 0.5$ \\
\hline
\end{tabular}



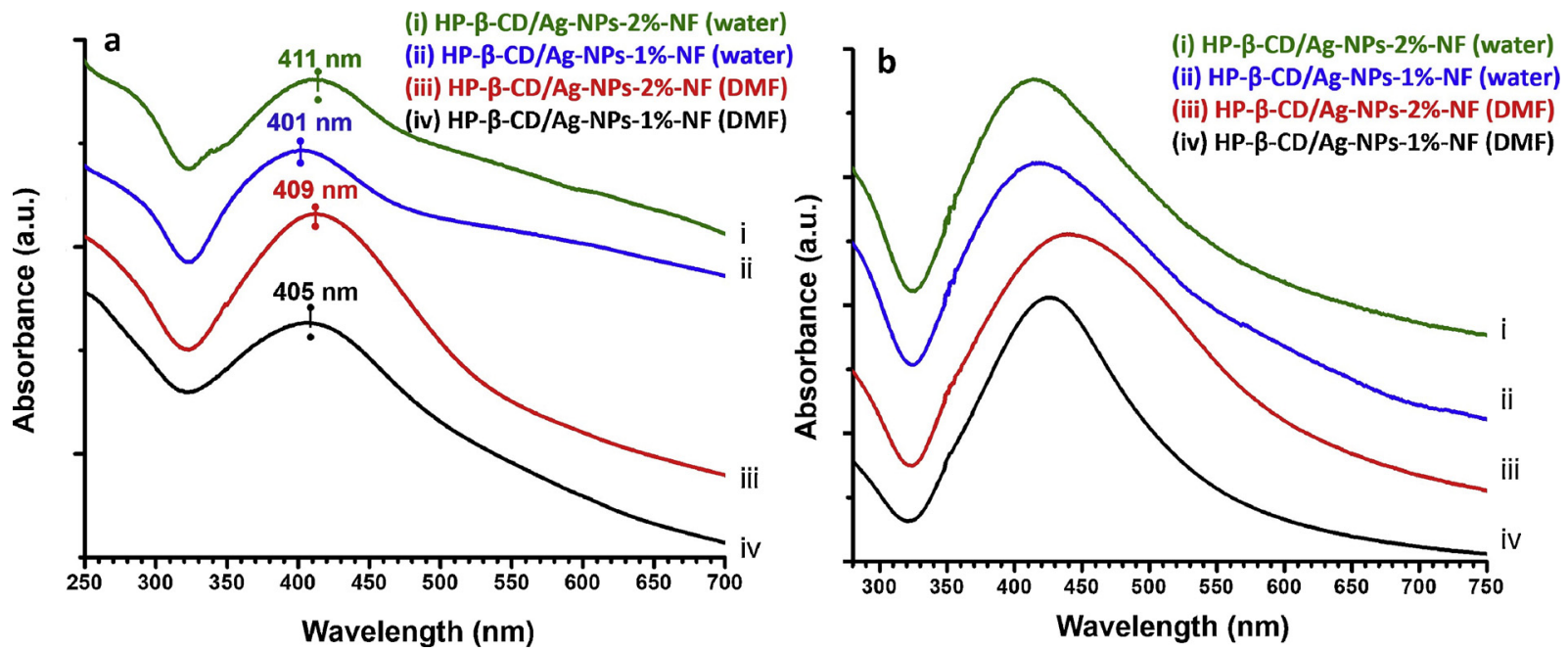

Fig. 5. (a) The solid-state UV-vis spectra of the HP- $\beta$-CD/Ag-NPs nanofibers and (b) the liquid-state UV-vis spectra of the HP- $\beta$-CD/Ag-NPs solutions.
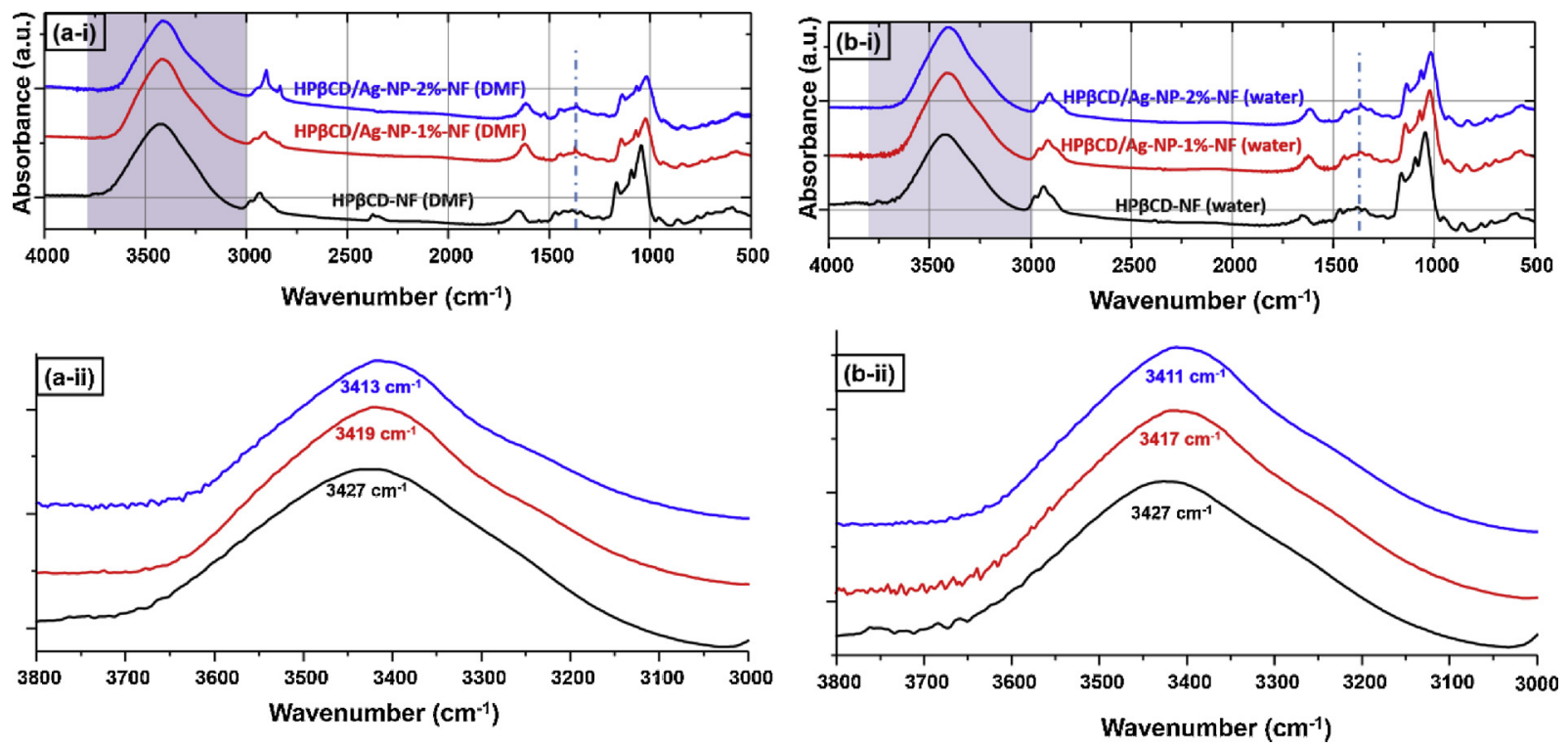

Fig. 6. FTIR spectra of the pure HP- $\beta$-CD nanofibers and HP- $\beta$-CD/Ag-NPs nanofibers produced at different formulations. (a-i, a-ii) The nanofibers produced from DMF solutions. (b-i, b-ii) The nanofibers generated from aqueous solutions.

interactions between $\mathrm{CD}$ and Ag-NPs, which enables the stabilization of the Ag-NPs during the particle growth. Similar shifts were reported for Au-NPs loaded CD nanofibers owing to the interactions between AuNPs and CD molecules (Celebioglu \& Uyar, 2013). Furthermore, a small peak appeared at $1385 \mathrm{~cm}^{-1}$ for the HP- $\beta$-CD/Ag-NPs nanofibers due to the stretching band of $\mathrm{NO}_{3}$ related to $\mathrm{AgNO}_{3}$ precursor (Fig. $6 \mathrm{a}$ and b).

The presence of Ag-NPs in the HP- $\beta$-CD/Ag-NPs nanofibers was also confirmed by surface-enhanced Raman scattering (SERS) analysis (Fig. 7). Ag-NPs have been commonly exploited as a SERS active substrate (Yang et al., 2015). For SERS measurements, the homogenous distribution of Ag-NPs in the solution or material is highly critical: there are several irresistible factors that can lead to the weakening or disappearing of the repulsive forces. However, the use of CD molecules can stabilize them and prevent their aggregation. The nanofibers with $1 \mathrm{wt}$. $\% \mathrm{Ag}$ were deformed during the measurements due to excessive heating, and therefore, the SERS measurements were performed on the nanofibers containing $0.1 \mathrm{wt}$.\% Ag-NPs. The Raman bands of the HP- $\beta$ $\mathrm{CD}$ molecules were weak for pure HP- $\beta$-CD nanofibers. Whereas, the presence of $0.1 \mathrm{wt} . \%$ Ag-NPs led to drastic changes in the Raman spectrum, where all peaks were clear and sharp. The Raman bands of the HP- $\beta$-CD appeared in following ranges: $800-1500 \mathrm{~cm}^{-1}, 2800$ $3000 \mathrm{~cm}^{-1}$ (CH stretching of hydroxypropyl (HP) group), and $3100-3600 \mathrm{~cm}^{-1}$ (OH stretching), and agree well with literature reports (Zoppetti, Puppini, Ospitali, \& Fini, 2007). Regardless of the solvent-type used in the production of the HP- $\beta$-CD/Ag-NPs nanofibers, the intensities of Raman bands of the $\mathrm{CD}$ molecules were drastically enhanced because of the presence of homogenous distributed Ag-NPs in the fiber matrices (Fig. 7, insets). It is known that the localized surface plasmon resonance of the nanoparticles can cause strong and highly localized fields for SERS (Wu, Li, Lin, \& Chen, 2017). In this context, the distribution of the Ag-NPs was explored by TEM analysis. Fig. 7 (insets) shows the TEM images of the respective nanofiber samples containing $0.1 \mathrm{wt} . \% \mathrm{Ag}$. Even though the nanoparticle content was very low, TEM images showed the dark dots related to the formed Ag-NPs without any aggregation: they were homogenously distributed throughout the nanofiber matrix as observed for the HP- $\beta$-CD/Ag-NPs nanofibers containing 1 or 2 wt.\% Ag.

The structural properties of the nanofibers were explored by XRD analysis. Unlike native $\beta$-CD (Fig. $8 \mathrm{a}$ ), HP- $\beta$-CD is an amorphous compound and gives a broad peak centered at $19^{\circ}$ (Fig. 8b). Apart from this 

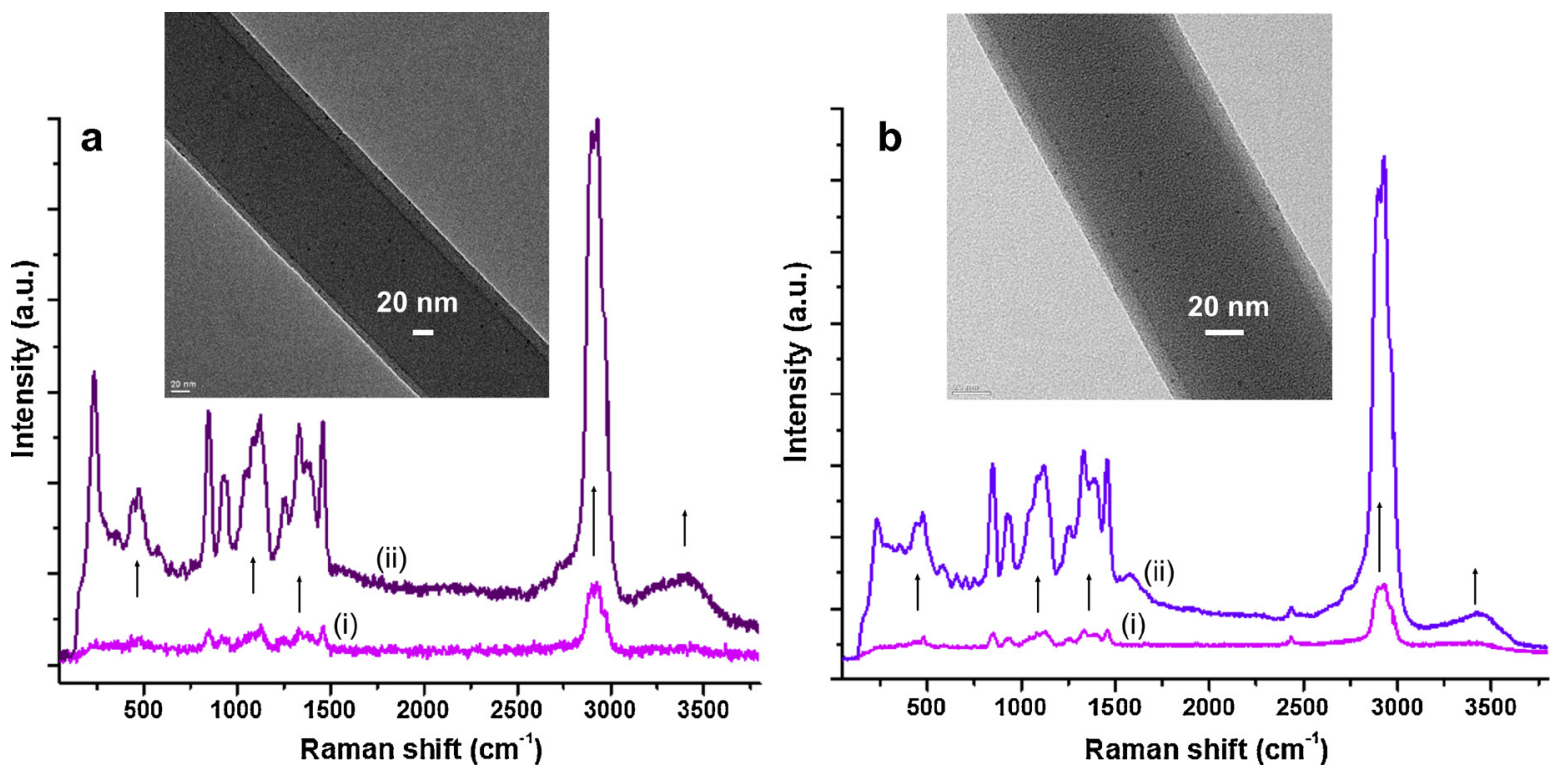

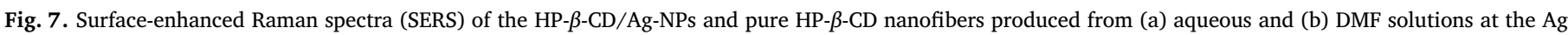
loading of $0.1 \mathrm{wt} . \%$. Insets show the TEM images of the respective HP- $\beta$-CD/Ag-NPs nanofibers having $0.1 \mathrm{wt} . \% \mathrm{Ag}$ loading.

(a)
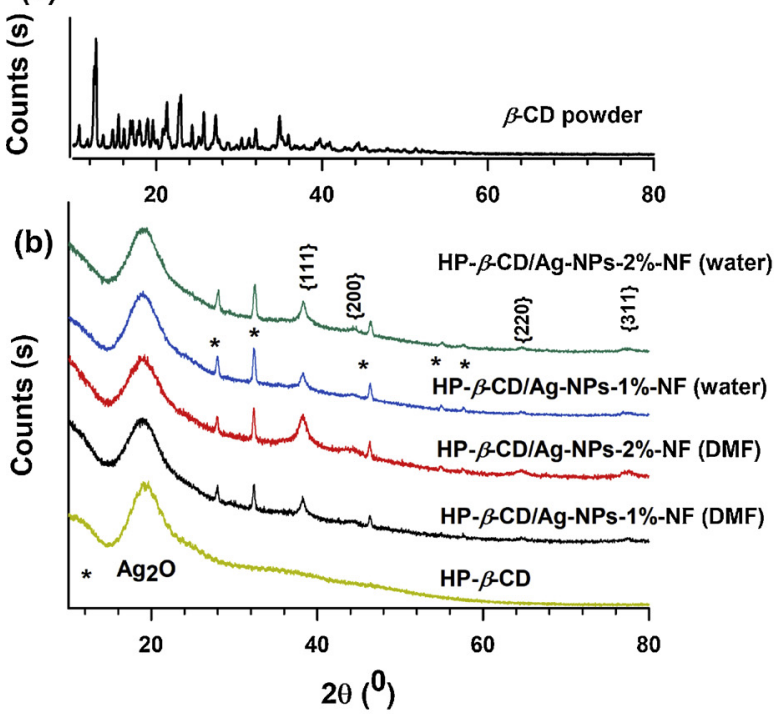

$2 \theta(0)$

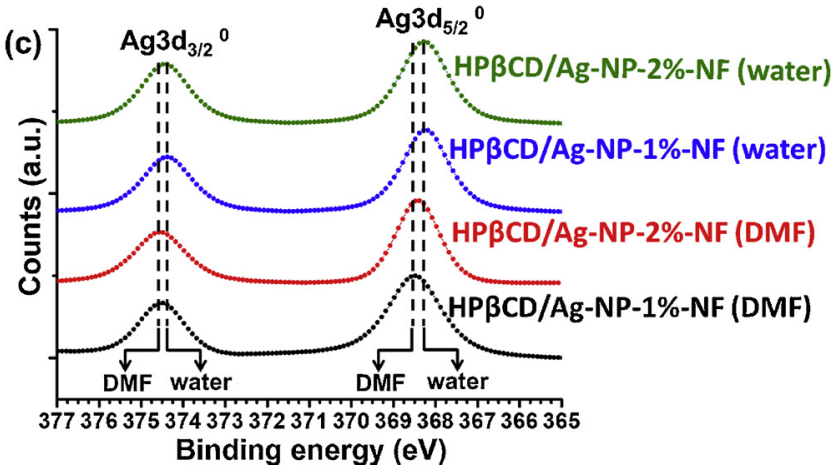

Fig. 8. (a) Wide-angle XRD patterns of the pure $\beta$-CD powder (a) and pure HP- $\beta$ $\mathrm{CD}$ and HP- $\beta$-CD/Ag-NPs nanofibers (b) produced at different formulations. (c) The deconvoluted Ag $3 \mathrm{~d}$ spectra of the HP- $\beta$-CD/Ag-NPs nanofibers.

broad peak, many small peaks related to Ag-NPs appeared between 25 and $80^{\circ}$. The diffractions peaks at $38.4^{\circ}, 44.4^{\circ}, 64.6^{\circ}$ and $77.6^{\circ}$ can be attributed to $\{111\},\{200\},\{220\}$ and $\{311\}$ crystalline planes of a fcc
Ag (Celebioglu et al., 2014). Additional diffraction peaks appeared at $2 \theta$ of $28^{\circ}, 32.4^{\circ}, 46.4^{\circ}$ and $57.9^{\circ}$ due to the presence of oxidized Ag $\left(\mathrm{Ag}_{2} \mathrm{O}\right)$. The chemical states of $\mathrm{Ag}$ in the nanofibers were explored by XPS analysis. Fig. 8c shows the deconvoluted Ag 3d XPS spectra of the samples. Two broad peaks were observed at 368.5 and $374.5 \mathrm{eV}$ related to $3 d_{3 / 2}$ and $3 d_{5 / 2}$ orbits and separated by $6 \mathrm{eV}$ (Fig. $8 \mathrm{c}$ ). These values are consistent with literature reports (Liu et al., 2015; Tzani, Koutsoukos, Koukouzelis, \& Detsi, 2017). However, negative shifts were observed at the binding energy for the HP- $\beta$-CD/Ag-NPs nanofibers produced from aqueous solutions than those electrospun from DMF solutions due to the higher ratio of $\mathrm{Ag}_{2} \mathrm{O}$ in the nanofiber sample produced in water (Fig. 8c). These findings were confirmed by XRD analysis with the appearance of peaks related to oxidized Ag (see Fig. 8b).

The antibacterial properties of the HP- $\beta$-CD/Ag-NPs nanofibers were explored against Gram-negative (E. coli) and Gram-positive ( $S$. aureus) bacteria (Fig. 9). The nanofibers produced in the absence and presence of the Ag-NPs were tested for comparison. The minimize possible errors, the samples were taken at different locations from the same fibrous mat, which was placed on $E$. coli and $S$. aureus grown agar plates and visualized after $24 \mathrm{~h}$ incubation. Afterwards, the diameter of the inhibition zones was measured and averaged. No antibacterial activity was observed for pure HP- $\beta$-CD nanofibers. On the other hand, the incorporation of the Ag-NPs into the nanofibers caused antibacterial activity, and the fibers showed significant inhibition against bacterial growth (Fig. 9). Since pure CD nanofibers do not have any antibacterial activity, the antibacterial activity of the HP- $\beta$-CD/Ag-NPs composite nanofibers is directly associated to the presence of the formed Ag-NPs. However, the increase of $\mathrm{Ag}$ content by two-fold led to $\sim 10 \%$ enhancement in the antibacterial activity, demonstrating that even $1 \mathrm{wt} . \%$ of Ag-NPs is high enough to possess antibacterial activity. The respective diameters of inhibition zones for the nanofiber samples containing $1 \mathrm{wt} . \% \mathrm{Ag}$ were found as $1.07 \pm 0.038$ and $1.16 \mathrm{~cm}$ for $E$. coli and $S$. aureus, respectively. Similar results were obtained with Ag-NPs embedded electrospun poly(L-lactide) fibers and antibacterial activity, i.e., $98.5 \%$ and $94.2 \%$ against $S$. aureus and $E$. coli, was observed, demonstrating high antibacterial activity of Ag-NPs (Xu et al., 2006).

\section{Conclusion}

The nanocomposite nanofibers of HP- $\beta$-CD with the in situ formed Ag-NPs were successfully produced by solution electrospinning. CDs are 

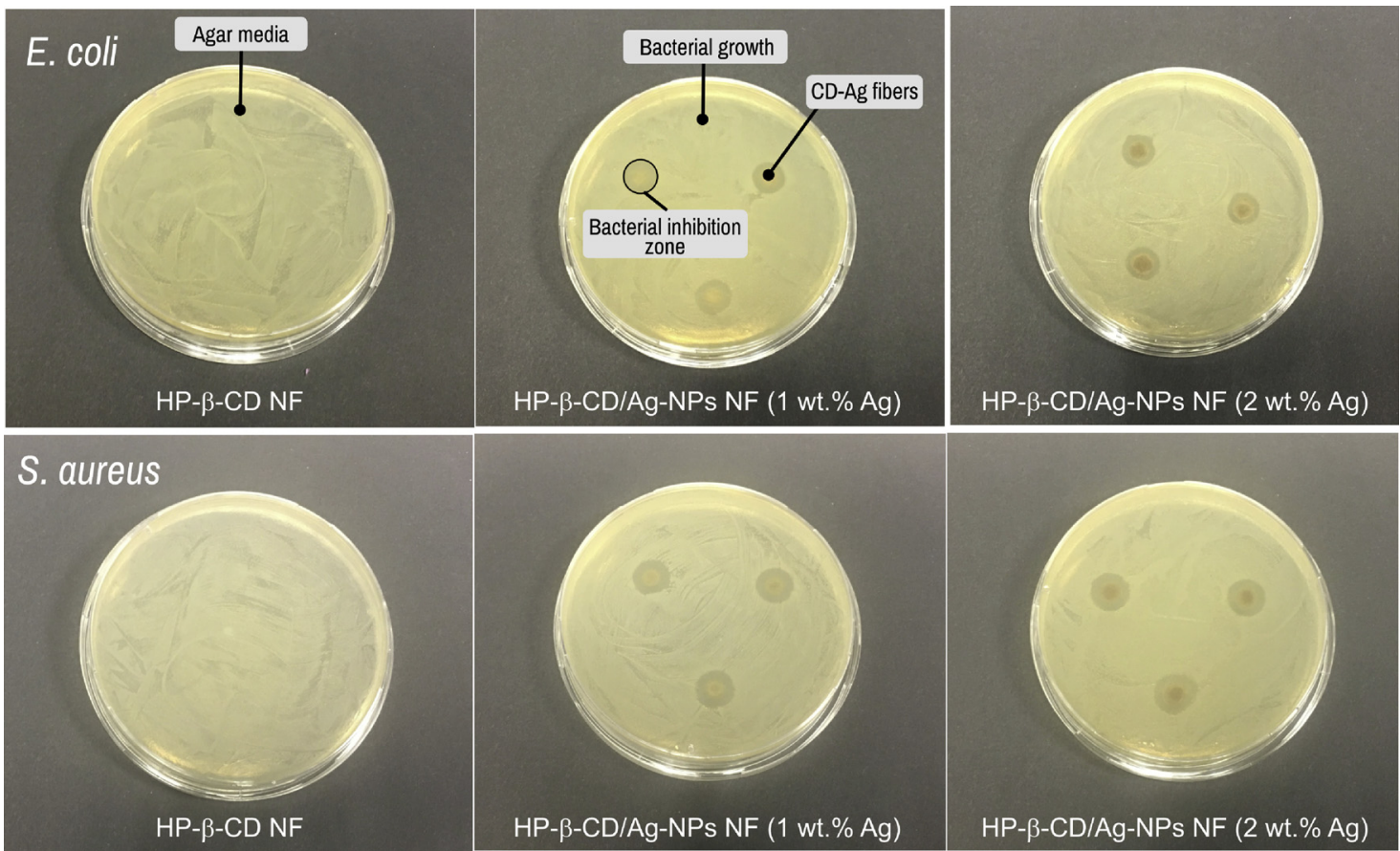

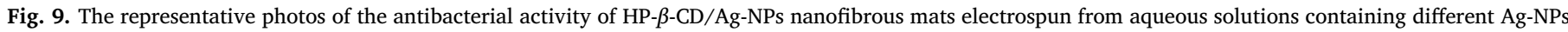
contents, which were tested against $E$. coli (top panel) and $S$. aureus (bottom panel).

cyclic oligosaccharides obtained from starch and therefore, environmentally benign molecules, which can be used as the reducing and stabilizing agent during the synthesis of noble-metal nanoparticles. CD could catalyze the reduction of $\mathrm{Ag}(\mathrm{II})$ to metallic $\mathrm{Ag}(0)$ without the need of any reducing agent. Further, the HP- $\beta$-CD/Ag-NPs nanofibers could be produced without the need of a polymeric carrier. The fiber size could be tailored depending on the solvent type used. The fibers with smaller diameters were observed in the presence of DMF as the solvent. Regardless of solvent-type, the mean fiber diameter increased with an increasing Ag loading. The formed Ag-NPs were in the size range of $2-5 \mathrm{~nm}$ depending on the $\mathrm{AgNO}_{3}$ content and solvent system used. The formation of larger Ag-NPs was observed from the DMF-based system. The TEM and STEM analyses of the HP- $\beta$-CD/Ag-NPs nanofibers clearly revealed the presence of the embedded Ag-NPs in the fiber matrix. UV-vis experiments revealed the characteristic SPR band of AgNPs in the wavelength range of 300-500 nm. Likewise, SERS measurement confirmed the presence of Ag-NPs over the enhancement of the Raman bands of the HP- $\beta$-CD fiber due to the highly plasmonic properties of the Ag-NPs. The WAXS analysis revealed the polycrystalline structure of the formed Ag-NPs over $\{111\},\{200\},\{220\}$ and $\{311\}$ crystalline planes. The HP- $\beta$-CD/Ag-NPs nanofibers showed an antibacterial activity against the growth of $E$. coli and $S$. aureus over $24 \mathrm{~h}$ treatment. The concept presented here is not limited to the production of electrospun CD fibers loaded with the in situ formed Ag-NPs but can be extended to generate functional $C D$ fibers embedded with other types of noble metal nanocrystals. Moreover, since CDs are functional molecular cages that can be adapted for drug delivery and adsorption-based applications, the resultant materials can be exploited in multipurpose applications in addition to their antibacterial application.

\section{References}

Abdelgawad, A. M., Hudson, S. M., \& Rojas, O. J. (2014). Antimicrobial wound dressing nanofiber mats from multicomponent (chitosan/silver-NPs/polyvinyl alcohol) systems. Carbohydrate Polymers, 100, 166-178.

Bannerman, D. D., Paape, M. J., Lee, J.-W., Zhao, X., Hope, J. C., \& Rainard, P. (2004). Escherichia coli and Staphylococcus aureus elicit differential innate immune responses following intramammary infection. Clinical and Diagnostic Laboratory
Immunology, 11(3), 463-472.

Bhui, D. K., Bar, H., Sarkar, P., Sahoo, G. P., De, S. P., \& Misra, A. (2009). Synthesis and UV-vis spectroscopic study of silver nanoparticles in aqueous SDS solution. Journal of Molecular Liquids, 145(1), 33-37.

Celebioglu, A., \& Uyar, T. (2012). Electrospinning of nanofibers from non-Polymeric systems: Polymer-free nanofibers from cyclodextrin derivatives. Nanoscale, 4(2), 621-631.

Celebioglu, A., \& Uyar, T. (2013). Green and one-step synthesis of gold nanoparticles incorporated into electrospun cyclodextrin nanofibers. RSC Advances, 3(26), 10197-10201.

Celebioglu, A., Aytac, Z., Umu, O. C. O., Dana, A., Tekinay, T., \& Uyar, T. (2014). Onestep synthesis of size-tunable Ag nanoparticles incorporated in electrospun PVA/cyclodextrin nanofibers. Carbohydrate Polymers, 99, 808-816.

Chanter, N., Hall, G. A., Bland, A. P., Hayle, A. J., \& Parsons, K. R. (1986). Dysentery in calves caused by an atypical strain of Escherichia coli (S102-9). Veterinary Microbiology, 12(3), 241-253.

Crini, G. (2014). Review: A history of cyclodextrins. Chemical Reviews, 114(21), 10940-10975.

Cui, H., Wu, J., Li, C., \& Lin, L. (2017). Improving anti-listeria activity of cheese packaging via nanofiber containing nisin-loaded nanoparticles. LWT - Food Science and Technology, 81, 233-242.

Cui, H., Bai, M., \& Lin, L. (2018). Plasma-treated poly(ethylene oxide) nanofibers containing tea tree oil/beta-cyclodextrin inclusion complex for antibacterial packaging. Carbohydrate Polymers, 179, 360-369.

Cui, H., Bai, M., Rashed, M. M. A., \& Lin, L. (2018). The antibacterial activity of clove oil/ chitosan nanoparticles embedded gelatin nanofibers against Escherichia coli 0157:H7 biofilms on cucumber. International Journal of Food Microbiology, 266, 69-78.

de Souza, V. C., Barros, C. H. N., Tasic, L., Gimenez, I. F., \& Teixeira Camargo, Z. (2018). Synthesis of cyclodextrin polymers containing glutamic acid and their use for the synthesis of Ag nanoparticles. Carbohydrate Polymers, 202, 11-19.

Destaye, A. G., Lin, C.-K., \& Lee, C.-K. (2013). Glutaraldehyde vapor Cross-linked nanofibrous PVA mat with in situ formed silver nanoparticles. ACS Applied Materials \& Interfaces, 5(11), 4745-4752.

Devi, L. B., \& Mandal, A. B. (2013). Self-assembly of Ag nanoparticles using hydroxypropyl cyclodextrin: Synthesis, characterisation and application for the catalytic reduction of p-nitrophenol. RSC Advances, 3(15), 5238-5253.

Du, W.-L., Niu, S.-S., Xu, Y.-L., Xu, Z.-R., \& Fan, C.-L. (2009). Antibacterial activity of chitosan tripolyphosphate nanoparticles loaded with various metal ions. Carbohydrate Polymers, 75(3), 385-389.

González-Sánchez, M. I., Perni, S., Tommasi, G., Morris, N. G., Hawkins, K., LópezCabarcos, E., ... Prokopovich, P. (2015). Silver nanoparticle based antibacterial methacrylate hydrogels potential for bone graft applications. Materials Science \& Engineering. C, Materials for Biological Applications, 50, 332-340.

Hong, K. H., Park, J. L., Sul, I. H., Youk, J. H., \& Kang, T. J. (2006). Preparation of antimicrobial poly(vinyl alcohol) nanofibers containing silver nanoparticles. Journal of Polymer Science Part B: Polymer Physics, 44(17), 2468-2474.

Huang, L., Yang, H., Zhang, Y., \& Xiao, W. (2016). Study on synthesis and antibacterial properties of Ag NPs/GO nanocomposites. Journal of Nanomaterials, 2016, 9. 
Huang, T., Meng, F., \& Qi, L. (2009). Facile synthesis and one-dimensional assembly of cyclodextrin-capped gold nanoparticles and their applications in catalysis and surface-enhanced raman scattering. The Journal of Physical Chemistry C, 113(31), 13636-13642.

Kaper, J. B., Nataro, J. P., \& Mobley, H. L. T. (2004). Pathogenic Escherichia coli. Nature Reviews Microbiology, 2, 123.

Kim, J. S., Kuk, E., Yu, K. N., Kim, J.-H., Park, S. J., Lee, H. J., ... Cho, M.-H. (2007) Antimicrobial effects of silver nanoparticles. Nanomedicine: Nanotechnology, Biology and Medicine, 3(1), 95-101.

Levine, M. M. (1987). Escherichia coli that cause diarrhea: Enterotoxigenic, enteropathogenic, enteroinvasive, enterohemorrhagic, and enteroadherent. Journal of Infectious Diseases, 155(3), 377-381.

Li, C., Fu, R., Yu, C., Li, Z., Guan, H., Hu, D., ... Lu, L. (2013). Silver nanoparticle/chitosan oligosaccharide/poly(vinyl alcohol) nanofibers as wound dressings: A preclinical study. International Journal of Nanomedicine, 8, 4131-4145.

Li, H., Chen, Q., Zhao, J., \& Urmila, K. (2015). Enhancing the antimicrobial activity of natural extraction using the synthetic ultrasmall metal nanoparticles. Scientific Reports, 5, 11033

Lin, L., Dai, Y., \& Cui, H. (2017). Antibacterial poly(ethylene oxide) electrospun nanofibers containing cinnamon essential oil/beta-cyclodextrin proteoliposomes. Carbohydrate Polymers, 178, 131-140.

Lin, L., Zhu, Y., Li, C., Liu, L., Surendhiran, D., \& Cui, H. (2018). Antibacterial activity of PEO nanofibers incorporating polysaccharide from dandelion and its derivative. Carbohydrate Polymers, 198, 225-232.

Lin, L., Zhu, Y., Thangaraj, B., Abdel-Samie, M. A. S., \& Cui, H. (2018). Improving the stability of thyme essential oil solid liposome by using $\beta$-cyclodextrin as a cryoprotectant. Carbohydrate Polymers, 188, 243-251.

Liu, R., Xian, Z., Zhang, S., Chen, C., Yang, Z., Li, H., \& Cao, H. (2015). Electrochemicalreduction-assisted assembly of ternary Ag nanoparticles/polyoxometalate/graphene nanohybrids and their activity in the electrocatalysis of oxygen reduction. RSC Advances, 5(91), 74447-74456.

Lustosa, A. K. M. F., de Jesus Oliveira, A. C., Quelemes, P. V., Plácido, A., da Silva, F. V., Oliveira, I. S., ... de Almeida Leite, J. R. S. (2017). In situ synthesis of silver nanoparticles in a hydrogel of carboxymethyl cellulose with phthalated-cashew gum as a promising antibacterial and healing agent. International Journal of Molecular Sciences, 18(11), 2399.

Maciollek, A., \& Ritter, H. (2014). One pot synthesis of silver nanoparticles using a cyclodextrin containing polymer as reductant and stabilizer. Beilstein Journal of Nanotechnology, 5(1), 380-385.

Makvandi, P., Jamaledin, R., Jabbari, M., Nikfarjam, N., \& Borzacchiello, A. (2018). Antibacterial quaternary ammonium compounds in dental materials: A systematic review. Dental Materials, 34(6), 851-867.

Martin-Trasanco, R., Cao, R., Esparza-Ponce, H. E., Montero-Cabrera, M. E., \& ArratiaPérez, R. (2017). Reduction of Au(III) by a $\beta$-cyclodextrin polymer in acid medium. A stated unattainable reaction. Carbohydrate Polymers, 175, 530-537.

Pande, S., Ghosh, S. K., Praharaj, S., Panigrahi, S., Basu, S., Jana, S., ... Pal, T. (2007). Synthesis of normal and inverted gold - silver core-shell architectures in $\beta$-cyclodextrin and their applications in SERS. The Journal of Physical Chemistry C, 111(29), 10806-10813.

Pastoriza-Santos, I., \& Liz-Marzán, L. M. (1999). Formation and stabilization of silver nanoparticles through reduction by N,N-dimethylformamide. Langmuir, 15(4), 948-951.

Patel, A. C., Li, S., Wang, C., Zhang, W., \& Wei, Y. (2007). Electrospinning of porous silica nanofibers containing silver nanoparticles for catalytic applications. Chemistry of
Materials, 19(6), 1231-1238.

Prochowicz, D., Kornowicz, A., \& Lewiński, J. (2017). Interactions of native cyclodextrins with metal ions and inorganic nanoparticles: Fertile landscape for chemistry and materials science. Chemical Reviews, 117(22), 13461-13501.

Qasim, M., Udomluck, N., Chang, J., Park, H., \& Kim, K. (2018). Antimicrobial activity of silver nanoparticles encapsulated in poly-N-isopropylacrylamide-based polymeric nanoparticles. International Journal of Nanomedicine, 13, 235-249.

Rujitanaroj, P.-o., Pimpha, N., \& Supaphol, P. (2008). Wound-dressing materials with antibacterial activity from electrospun gelatin fiber mats containing silver nanoparticles. Polymer, 49(21), 4723-4732.

Ruszczak, Z., \& Friess, W. (2003). Collagen as a carrier for on-site delivery of antibacterial drugs. Advanced Drug Delivery Reviews, 55(12), 1679-1698.

Sanghi, R., \& Verma, P. (2009). Biomimetic synthesis and characterisation of protein capped silver nanoparticles. Bioresource Technology, 100(1), 501-504.

Sharma, N., \& Baldi, A. (2016). Exploring versatile applications of cyclodextrins: An overview. Drug Delivery, 23(3), 729-747.

Shi, Q., Vitchuli, N., Nowak, J., Noar, J., Caldwell, J. M., Breidt, F., \& Zhang, X. (2011) One-step synthesis of silver nanoparticle-filled nylon 6 nanofibers and their antibacterial properties. Journal of Materials Chemistry, 21(28), 10330-10335.

Son, W. K., Youk, J. H., Lee, T. S., \& Park, W. H. (2004). Preparation of antimicrobia ultrafine cellulose acetate fibers with silver nanoparticles. Macromolecular Rapid Communications, 25(18), 1632-1637.

Tzani, A., Koutsoukos, S., Koukouzelis, D., \& Detsi, A. (2017). Synthesis and characterization of silver nanoparticles using biodegradable protic ionic liquids. Journal of Molecular Liquids, 243, 212-218.

Vilchis-Nestor, A. R., Sánchez-Mendieta, V., Camacho-López, M. A., Gómez-Espinosa, R. M., Camacho-López, M. A., \& Arenas-Alatorre, J. A. (2008). Solventless synthesis and optical properties of Au and $\mathrm{Ag}$ nanoparticles using Camellia sinensis extract. Materials Letters, 62(17), 3103-3105.

Wang, L., Hu, C., \& Shao, L. (2017). The antimicrobial activity of nanoparticles: Present situation and prospects for the future. International Journal of Nanomedicine, 12, 1227-1249.

Williamson, D. H., Maroudas, N. G., \& Wilkie, D. (1971). Induction of the cytoplasmic petite mutation in Saccharomyces cerevisiae by the antibacterial antibiotics erythromycin and chloramphenicol. Molecular and General Genetics MGG, 111(3), 209-223.

Wu, L.-A., Li, W.-E., Lin, D.-Z., \& Chen, Y.-F. (2017). Three-dimensional SERS substrates formed with plasmonic core-satellite nanostructures. Scientific Reports, 7(1), 13066.

Xu, X., Yang, Q., Wang, Y., Yu, H., Chen, X., \& Jing, X. (2006). Biodegradable electrospun poly(l-lactide) fibers containing antibacterial silver nanoparticles. European Polymer Journal, 42(9), 2081-2087.

Yang, L., Chen, Y., Li, H., Luo, L., Zhao, Y., Zhang, H., ... Tian, Y. (2015). Application of silver nanoparticles decorated with $\beta$-cyclodextrin in determination of 6 -mercaptopurine by surface-enhanced Raman spectroscopy. Analytical Methods, 7(16), 6520-6527.

Zhao, L., Wang, H., Huo, K., Cui, L., Zhang, W., Ni, H., ... Chu, P. K. (2011). Antibacterial nano-structured titania coating incorporated with silver nanoparticles. Biomaterials, 32(24), 5706-5716.

Zhuang, X., Cheng, B., Kang, W., \& Xu, X. (2010). Electrospun chitosan/gelatin nanofibers containing silver nanoparticles. Carbohydrate Polymers, 82(2), 524-527.

Zoppetti, G., Puppini, N., Ospitali, F., \& Fini, A. (2007). Solid state characterization of progesterone in a freeze dried 1:2 progesterone/HPBCD mixture. Journal of Pharmaceutical Sciences, 96(7), 1729-1736. 